УДК 502:911.37

\title{
ОЦЕНКА ЭКОЛОГИЧЕСКОГО СОСТОЯНИЯ И РЕКРЕАЦИОННОГО ПРИРОДОПОЛЬЗОВАНИЯ ГОРОДСКОГО ПРИРОДНОГО КОМПЛЕКСА ЛЕСОПАРКА «ОЛИМПИК» Г. ВОРОНЕЖ
}

\author{
О. В. Спесивый, С. В. Щербинина, С. Т. Севрюков \\ Военный учебно-научный центр ВВС «Военно-воздушная акаделия им. проф. Н. Е. Жуковского и \\ Ю. А. Гагарина», Россия \\ Воронежский государственный университет, Россия \\ Воронежский государственный педагогический университет, Россия
}

Поступила в редакиию 17 февраля 2018 г.

\begin{abstract}
Аннотация: В статье рассмотрена структура и особенности использования зеленого фонда городского округа город Воронеж, дана характеристика лесопарка спортивного комплекса «Олимпик», приведена методика оценки экологического состояния и рекреационного природопользования городских природных комплексов, проанализированы результаты оценки рекреационной нагрузки, анкетирования посетителей и рекреационной дигрессии лесопарка «Олимпик».
\end{abstract}

Ключевые слова: городской природный комплекс, рекреационное природопользование, рекреационная нагрузка, рекреационная дигрессия, спортивный комплекс «Олимпик».

Abstract: The article deals with the structure and features of the use of the green fund of the city district of Voronezh. The authors described the forest park of the sport complex «Olympic» and presented the methodology for assessing the ecological state and recreational environmental management of urban natural complexes. The results of evaluation of recreational load, survey of visitors and recreational digression of the forest park «Olympic» have been analyzed.

Key words: urban natural complex, recreational nature management, recreational load, recreational digression, sport complex «Olympic».

Природные комплексы в городских экосистемах имеют большое значение и выполняют ряд важнейших функций: средообразующую, санитарно-защитную, природоохранную, рекреационную и т.п. К ним относятся: городские и пригородные леса и лесопарки, парки, озелененные территории различного назначения, водные поверхности и долины рек.

С увеличением численности населения возрастают и рекреационные потребности жителей и требования к качеству окружающей среды. В то же самое время, интенсивное социально-экономическое развитие сопровождается ростом антропогенного воздействия, сокращением природных территорий, нарушением экологической устойчивости и деградацией окружающей среды в

(ㄷ Спесивый О. В., Щербинина С.В., Севрюков С. Т., 2019 целом. Город Воронеж в 2012 году перешел рубеж в 1 млн. жителей (1058,5 тыс. чел. на 2018 г.). Он тоже сталкивается с данными проблемами. Ситуация усугубляется особенностями функционально-планировочной структуры и характеризуется дестабилизацией экологического состояния Воронежской агломерации.

Площадь территории городского округа составляет 596 кв. км, общая площадь зеленых насаждений в границах городского округа равна 202,2 кв. км. Зеленый фонд города включает пригородные леса, лесопарки и городские зеленые насаждения. Система внутригородских зеленых насаждений складывается из насаждений общего пользования (парки, сады, скверы, бульвары, озелененные улицы), ограниченного пользования (посадки на территории детских, лечебных учреждений, промышленных предприятий), специально- 
го назначения (спортивные сооружения, ботанические парки, дендропарки, кладбища, питомники) [2].

Рекреационная нагрузка на природные комплексы Воронежа довольно высокая. При этом парки и скверы для отдыха используются крайне неравномерно.

Одним из наиболее популярных мест отдыха является лесопарк «Олимпик». Лесопарк представляет собой облагороженный лесной массив с дорожками, тропинками и трассами для катания на велосипедах, роликах, лыжах и просто для прогулок, расположенный на северной окраине города, на 9-м километре Московского шоссе - автотрассы А-134 по направлению к Москве. Территория включает 2 спортивных комплекса (CK) и прилегающий лесной массив. Общая площадь 948 га. Территория исследования ограничена на западе трассой А-134, на востоке - Воронежским водохранилищем, на севере - дорогой на турбазу Ветряк, на юге - дорогой на поселок Рыбачий).

Спортивный комплекс «Олимпик» (СК СДЮСШОР № 12) относится к специализированной детско-юношеской спортивной школе олимпийского резерва № 12 по лыжным гонкам (МБОУДОД СДЮСШОР № 12), его площадь составляет 10900 кв. м. Спортивно-оздоровительный комплекс (СОК) «Олимпик» был образован в 1999 году из переданной администрации города лыжной базы научно-производственного объединения «Тяжэкс», которая была создана еще в 1987 году. В октябре 2011 года Воронежская городская Дума приняла решение сменить статус СОК «Олимпик» с муниципального унитарного предприятия (МУП) на муниципальное бюджетное учреждение (МБУ) и присоединить его к СДЮСШОР № 12 [1]. Также на территории лесопарка размещается СК «Адмирал».

Непосредственно лесной массив относится к Правобережному лесничеству Пригородного лесхоза и имеет статус особо охраняемой природной территории и входит в состав государственного природного заказника областного значения «Воронежская нагорная дубрава» [1].

Территория находится на междуречье рек Дон - Воронеж, представляющем четвертую надпойменную донскую террасу с абсолютными отметками от 100 до 162 м, перекрытую валом четвертичного возраста из флювиогляциальных песков и супесей («Воронежский оз»), переходящую в долинный склон реки Воронеж [3, 6].

В почвенном покрове лесопарка преобладают серые и темно-серые лесные почвы различного механического состава - от тяжелых суглинистых до супесей. Растительный покров представлен комплексом с сохранившейся естественной дубравой и байрачными сообществами. Характерные сосновые насаждения относятся к искусственным. Породный состав лесопарка разнообразен. В древесном ярусе господствует дуб обыкновенный, также представлены ясень обыкновенный, клен платановидный, липа мелколистная, вяз гладкий, вяз шершавый. В густом подлеске представлены липа мелколистная, клен равнинный, лещина, бересклет бородавчатый, крушина ломкая, жостер слабительный, рябина обыкновенная. В травянистом покрове типичны дубравные виды, многие из которых являются лекарственными [2].

Животный мир, несмотря на близость к городу, достаточно богат и разнообразен. Часто встречается лесная соня, еще чаще попадается белка. Много мелких мышевидных грызунов - желтогорлая мышь, лесная мышь, рыжая (лесная) полевка, отмечена степная пеструшка. Иногда можно встретить кабана, лисицу. Типичные представители птиц - дятлы, зяблики, соловьи, лесные коньки, зарянки, содовые овсянки, дрозды [6].

СК «Олимпик» является излюбленным местом для занятий спортом и просто для активного отдыха горожан. На территории проложены трассы различной длины для проведения соревнований по лыжным гонкам, спортивному ориентированию, лыжероллерам и спидскейтингу, построены стадион, тир, пункты проката и общественного питания. В 2011 году была сооружена большая парковка для автомобилей. Здесь есть также кафе и пункты проката велосипедов, роликовых коньков, лыж, коньков.

В настоящее время СК «Олимпик» как лыжный спортивный комплекс с освещенной лыжероллерной трассой включен в реестр объектов спорта России и имеет сертификат объекта спорта. Кроме того, Управлением по Физической Культуре и Спорту Воронежской области, СК «Олимпик» внесен в список объектов спортивной инфраструктуры Воронежской области и для него выделяют три профильных вида спорта - лыжные гонки, лыжероллеры, катание на роликовых коньках (роллер спорт). Спортивный объект находится в ведении Управления Физической культуры и Спорта администрации городского округа город Воронеж. Спорткомплекс имеет сертификат гомологации лыжных трасс на 5 км, 10 км, 12,5 км, 15 км, кроме того, лицензию как место осуществления образовательной деятельности, на его территории 
реализуется программа спортивной подготовки, дополнительная предпрофессиональная программа физкультурно-спортивной направленности по виду спорта лыжные гонки. СК «Олимпик» является региональным центром по сдаче норм ГТО.

На территории СК «Олимпик» работают спортивные федерации: «Федерация лыжных гонок», «Федерация лыжероллеров», «Федерация велоспорта», «Федерация спортивного ориентирования», «Федерация легкой атлетики», «Федерация Роллер Спорта Воронежской области».

Ежегодно на комплексе проводится более 50 соревнований от чемпионатов России, области и города, до спортивно-массовых мероприятий предприятий и образовательных учреждений. На объектах комплекса проводятся спортивные мероприятия российского уровня. Особую популярность получили ежегодные массовые спортивные соревнования, такие как: «Лыжня России» - количество участников от 8000 до 10000 человек; «Кросс нации» - количество участников до 10000 человек; «Российский Азимут»- участвует более 5000 человек; «Зеленый марафон» - участвуют от 3000 до 5000 человек; Лыжный марафон памяти Лопатина - 500-800 спортсменов [10].

Помимо массовых соревнований проводятся узкоспециализированные соревнования, чемпионаты и первенства. Ежегодно в городе Воронеже проходит крупнейший в России международный роллер-фестиваль «Инлайн Весна Воронеж», в рамках которого проводится марафон 42 км на роликовых коньках, который является важнейшим среди марафонских гонок в России.

В настоящее время на базе СК «Олимпик» на безвозмездной основе проводят учебно-тренировочные занятия ряд СДЮСШОР: 1) СДЮСШОР № 12
- лыжные гонки; 2) СДЮСШОР № 18 - спортивное ориентирование; 3) СДЮСШОР № 8 - велоспорт; 4) СДЮСШОР №5 - легкая атлетика; 5) ДЮСШ № 24 - хоккей с шайбой (летняя подготовка); 6) СДЮСШОР № 1 - областная многофункциональная школа.

Кроме того, осуществляют тренировочные занятия детский футбольный клуб, федерации лыжероллеров и пейнтбола, Воронежский любительский лыжный союз. Здесь также состоятся учебно-тренировочные сборы команды России по лыжным гонкам. Всего около 1500 человек повышают свое спортивное мастерство на базе данного комплекса. Ежедневно на базе комплекса отдыхают и занимаются оздоровительными физкультурными мероприятиями до 2000 человек, а в выходные и праздничные дни до 5000 человек.

Присутствие человека оказывает существенное влияние на состояние территории. Конкретным проявлением антропогенного воздействия является густая сеть тропинок, прогалин и полян в лесу с сильно уплотненной почвой, кострища и свалки бытового мусора. Так же к антропогенным воздействиям отнесены сборы цветов, ягод, наплыв туристов и отдыхающих [8].

На территории спортивного комплекса ведется благоустройство территории, а именно: искусственное насаждение деревьев и организация маршрутов для рекреантов (например, Большая Воронежская экологическая тропа).

Нами с 2011 года проводятся исследовательские работы по оценке экологического состояния природного комплекса и влиянию рекреационной нагрузки. В ходе исследования оценено количество рекреантов, густота тропиночной сети, количество мест свалок мусора на территории, состояние и

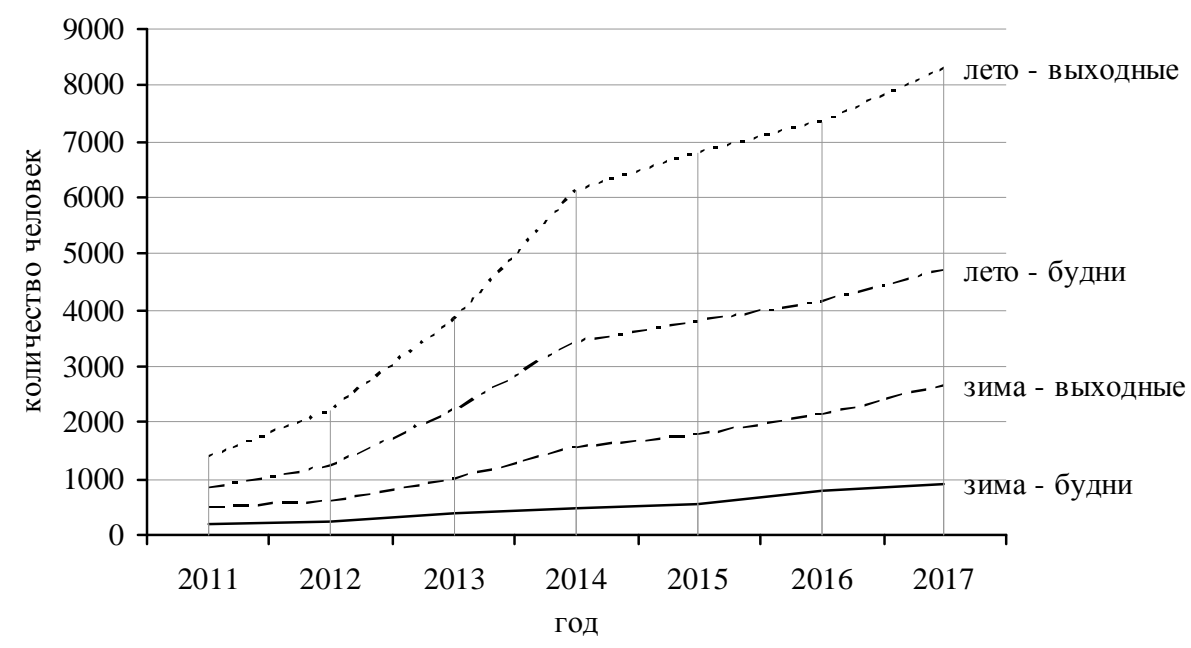

Puc. 1. Средняя посещаемость СК «Олимпик», человек/день 


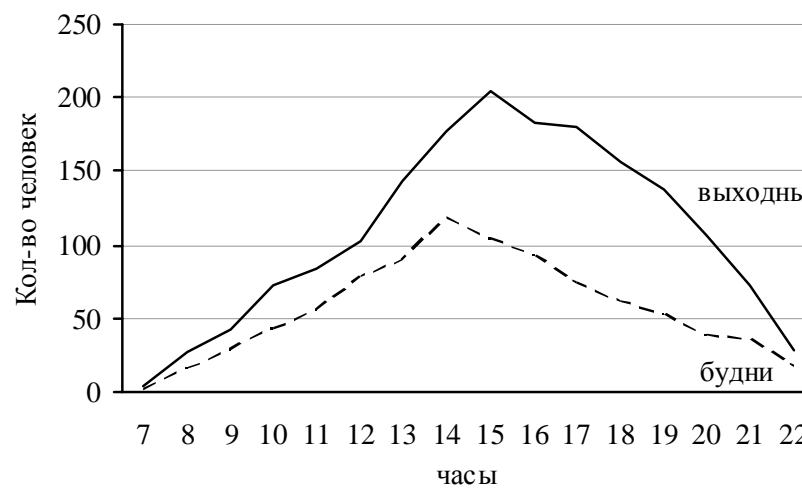

Puc. 2. Средняя посещаемость СК «Олимпик» в зимний период (2017 г.), человек/час

структура фитоценозов (количество светолюбивых видов, количество теневыносливых, а также видоизменение древесного яруса), изменение физических свойств лесной подстилки и почвенного покрова.

Учет истинного количества отдыхающих всегда самая затруднительная задача в подобных исследованиях. Оценка посещаемости проводилась на участках, охватывающих все растительные ассоциации лесопарка на заложенных пробных площадках. Полученные результаты являются приблизительными, так как одни посетители могут использовать территорию лесопарка для отдыха и оказывать площадное воздействие, а другие - только пересекать ее, двигаясь по тропинкам, и оказывать линейное воздействие.

Лесопарковые биогеоценозы обладают разной устойчивостью к антропогенной нагрузке, поэтому неодинаково противостоят рекреационному давлению. Роль допустимых рекреационных нагрузок, может быть лучше понята, если рассматривать их с точки зрения типа воздействия определенной интенсивности и способа передвижения: свободного (площадное воздействие) или по тропам (линейное).

Отмечается, что линейное движение ограничивает ущерб природе. При рассредоточенном отдыхе оно локализует его на площади, составляющей меньше 0,1\% используемой территории. Опасные признаки деградации почвенно-растительного покрова исчезают уже на расстоянии 1,52 м от центра тропы при ее ширине до 2 м. Линейное распределение нагрузок сглаживает и упрощает их отношения с пространством и временем, растягивая допустимые интервалы, найденные для единиц площади, и преобразует критическое давление рекреации в приемлемое. Установлено, что образование тропы идет быстро - это делает двухнедельный проход нескольких человек в день [8].

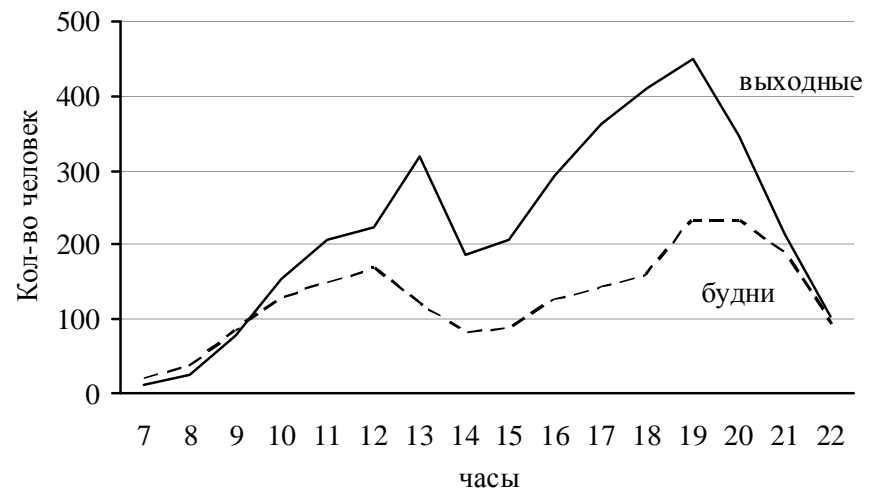

Puc. 3. Средняя посещаемость СК «Олимпик» в летний период (2017 г.), человек/час

Оценка количества рекреантов, находящихся на территории в разные промежутки времени, проводилась нами в зимний и летний сезоны в будние и выходные дни путем подсчета посетителей, прошедших или отдыхающих на выделенных участках в течение одного часа. Были получены следующие результаты (рис. 2-3).

Сравнивая показатели с 2011 по 2017 год (рис. 1), можно сделать вывод, что количество посещений территории за это время существенно возросло (в 5-6 раз) с 200-500 до 900-3500 человек в день в зависимости от дня и сезона года, что говорит о постоянно возрастающей антропогенной нагрузке на природный комплекс. Значения при проведении массовых мероприятий еще выше (например, Всероссийские массовые соревнования «Лыжня России»). Это связано с ростом населения и его рекреационных потребностях, благосостоянием (так как значительно увеличивается посещение именно на личном автотранспорте), развитием городской инфраструктуры, особенно в близлежащих районах (реконструкция и строительство дорог, торговых центров, жилых кварталов).

Зимой в течение дня наблюдается один пик наплыва людей в обеденные часы. В вечерние часы рекреанты на территории комплекса также присутствуют, так как работает освещение (рис. 2). В летние месяцы в течение дня наблюдается 2 пика наплыва людей, в обеденные часы и вечером после работы (рис. 3).

Для определения «портрета» среднестатистического посетителя лесопарка, нами в 2015 году было проведено анкетирование (рис. 4).

Рассматривая рекреационную нагрузку в течение всего периода наблюдений можно отметить следующее: 1) в зимний период с установлением постоянного снежного покрова начинается лыжный сезон, жителям становятся доступны и дру- 
Оценка экологического состояния и рекреационного природопользования городского природного комплекса лесопарка «Олимпик» г. Воронеж

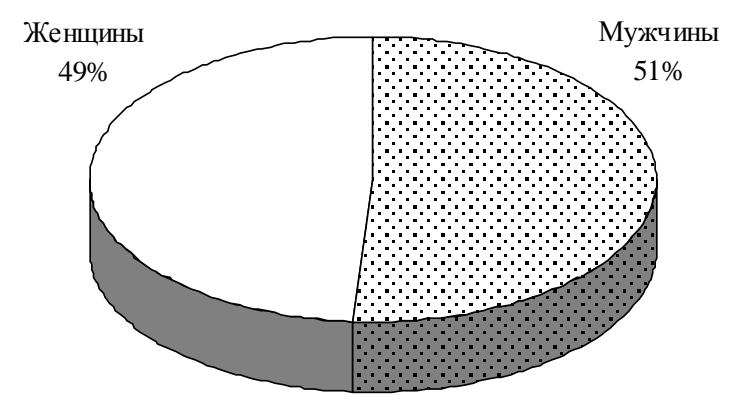

А. Пол

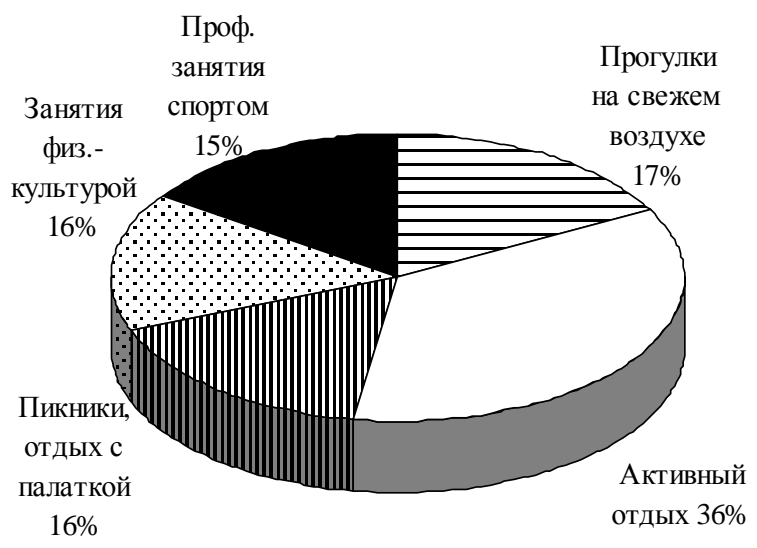

В. Цели посещения
56 и

старше,

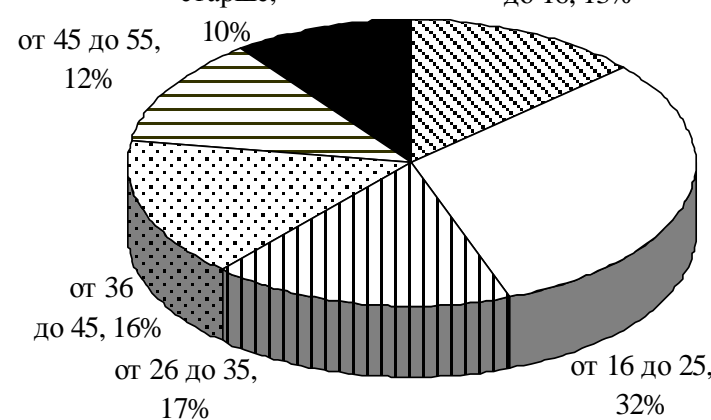

Б. Возраст, годы

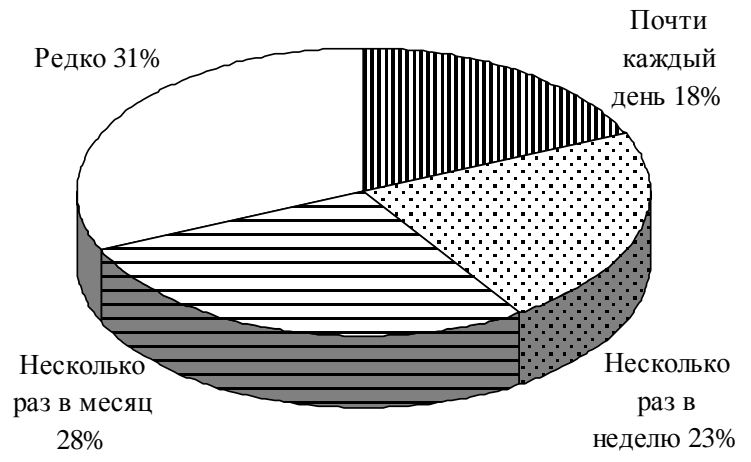

Г. Частота посещения

Puc. 4. Результаты анкетирования посетителей СК «Олимпик» в 2015 году

гие виды зимнего активного отдыха (коньки, санки и т.д.), наблюдается достаточно высокий уровень отдыхающих; 2) в конце зимы - начале весны тает снежный покров, устанавливается пасмурная погода, наступает межсезонье, уровень отдыхающих снижается на непродолжительное время; 3) со второй половины весны происходит рост рекреационной нагрузки, что связано с улучшением погодных условий, общей эмоциональной усталостью от зимы и бело-серых пейзажей, цветением эфемероидов и общей привлекательностью лесопарка как зеленого массива; 4) начало лета - начало полевых практик у студентов (по естественнонаучным дисциплинам, а также по живописи и т.п.), экскурсий и т.д. В весенне-летний период наблюдается максимальная рекреационная нагрузка [9]; 5) в середине и конце лета посещаемость сокращается, но незначительно, так как часть жителей уезжают из города (в отпуска, на каникулы, на дачи). Однако с каждым годом возрастает число горожан, не имеющих возможности еженедельно выезжать за город и поэтому посещаемость парка в этот период поддержива- ется в основном за счет них. Весенне-летняя рекреация несколько выше летне-осенней; 6) осенью посещаемость уменьшается, что связано с погодными условиями, увяданием растительности и снижением привлекательности лесопарка для отдыха.

Для комплексной оценки экологического состояния природного комплекса мы использовали методику Н. С. Казанской $[4,5]$, которая выделяет 5 стадий рекреационной дигрессии.

1. Деятельность человека не внесла в лесной комплекс никаких заметных изменений.

2. Рекреационное воздействие человека выражается в установлении редкой сети тропинок, в появлении среди травянистых растений некоторых светолюбивых видов, в начальной фазе разрушения подстилки.

3. Тропиночная сеть сравнительно густа, в травянистом покрове преобладают светолюбивые виды, начинают появляться и луговые травы, мощность подстилки уменьшается, на внетропиночных участках возобновление леса все еще удовлетворительное. 


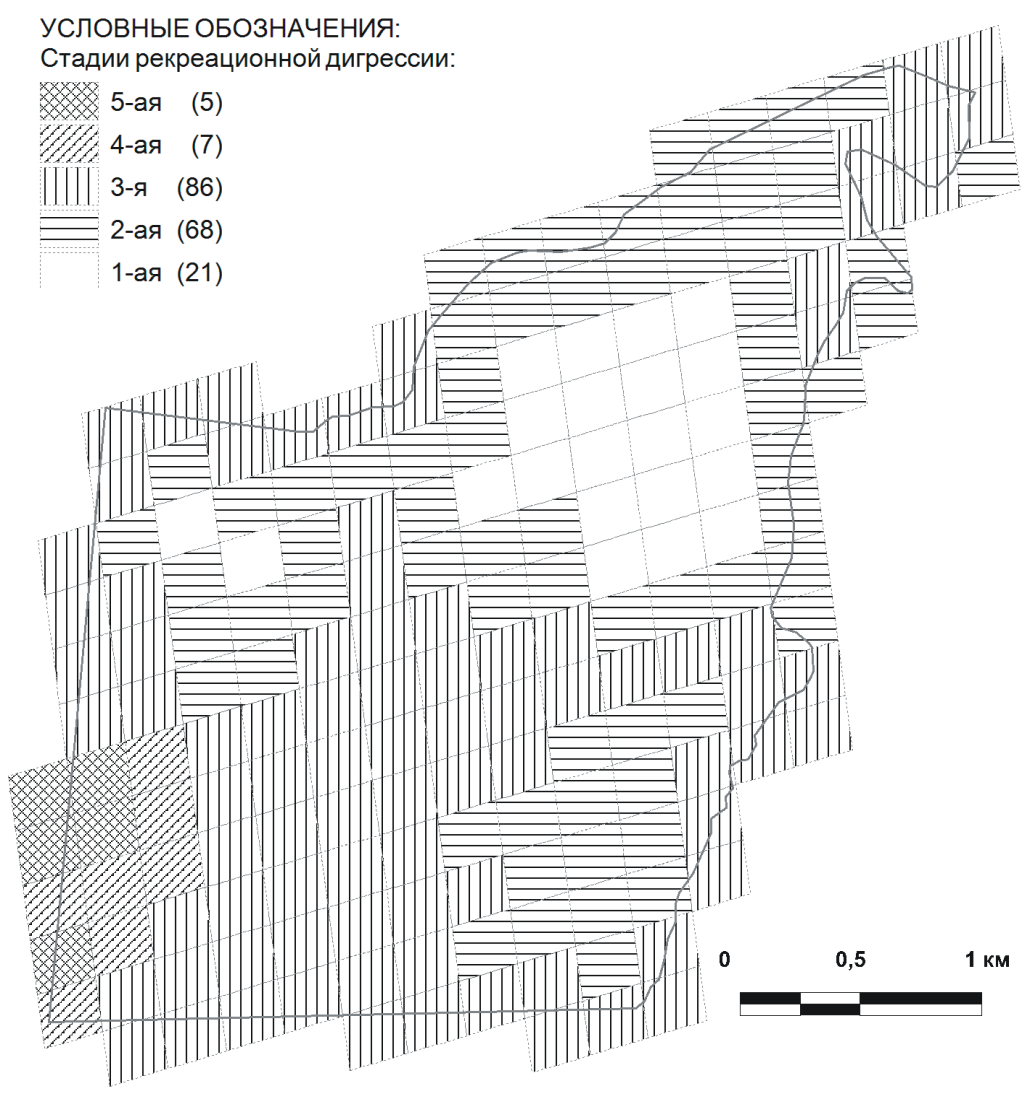

Puc. 5. Экологическое состояние лесопарка «Олимпик»

4. Тропинки густой сетью опутывают лес, в составе травянистого покрова количество собственно лесных видов незначительно, жизнеспособного подроста молодого возраста (до 5-7 лет) фактически нет, подстилка встречается фрагментарно у стволов деревьев.

5. Полное отсутствие подстилки и подроста, отдельными экземплярами на вытоптанной площади - сорные и однолетние виды трав.

Граница устойчивости природного комплекса, т.е. предел, после которого наступают необратимые изменения, проходит между 3 и 4 стадиями. Соответственно за предельно допустимую принимается та нагрузка, которая соответствует 3 стадии дигрессии. Необратимые изменения в природном комплексе начинаются на 4 стадии, а угроза гибели лесных насаждений - на 5 стадии [4].

Исследуемая территория лесопарка «Олимпик» площадью 948 га была разделена регулярной сеткой на квадраты $250 \times 250$ метров. В каждом квадрате на основе наблюдений за состоянием древесной растительности и почвенного и травянистого покрова, наличии мест свалок мусора, была определенна стадия рекреационной дигрессии. Оказалось, что из 184 квадратов первую стадию дигрессии имеют 21 квадрат (11,41\%); вторую стадию дигрессии имеют 68 квадратов $(35,33 \%)$; третью стадию имеют 86 квадратов $(46,74 \%)$; четвертую стадию имеют 7 квадратов $(3,80 \%)$; пятую стадию имеет 5 квадратов $(2,72 \%)$.

Таким образом, начальные стадии дигрессии характерны почти для $47 \%$ территории лесного массива, еще столько же находятся на предпороговом уровне (третья стадия) и испытывает предельно допустимые рекреационные нагрузки. Для 6,5\% территории отмечаются запредельные воздействия, ведущие к необратимым процессам деградации. Более высокая стадия дигрессии характерна для участков, где находится стадион, спортплощадки и основные асфальтированные дорожки для прогулок, а также участки, находящиеся рядом с автомобильными дорогами, с которых имеются съезды в лесной массив. В целом, природный комплекс находится на третьей стадии рекреационной дигрессии (рис 5).

Необходимо отметить, что нагрузка на природный комплекс за время наблюдений значительно возросла. Это связано с ростом рекреационных потребностей населения, (важно отметить существенное увеличение посещений именно на личном 
автотранспорте), развитием в близлежащих районах городской инфраструктуры: проводимая реконструкция и строительство дорог, жилых коттеджных кварталов, центров покупок и развлечений.

Для сохранения данного уникального природного комплекса необходимы комплексные меры по организации рационального рекреационного природопользования, режима охраны природы, экологического просвещения отдыхающих, а также лесохозяйственные мероприятия, направленные на повышение и сохранение долговечности насаждений в условиях высокой антропогенной нагрузки. Главным инструментом снижения рекреационной нагрузки, вплоть до ее исключения на определенных участках, является благоустройство рекреационных территорий, позволяющее повысить аттрактивность участков с высоким классом устойчивости, акцентировать рекреационное пользование на менее агрессивных формах рекреации без снижения комфортности отдыха.

\section{СПИСОК ЛИТЕРАТУРЫ}

1. Государственный природный заказник областного значения «Воронежская нагорная дубрава» / Департамент природных ресурсов и экологии Воронежской области. - http//:www.dprvrn.ru/index.php/work/ osobo...prirodnye.../329-210613oopt

2. Григорьевская А. Я. Анализ флоры города Воронежа / А. Я. Григорьевская, В. Я. Хрипякова, О. П. Быковская // Геоэкологические проблемы устойчивого развития городской среды. - Воронеж, 1996. - С. 236-238.

3. Грищенко М. Н. Геологическое строение территории учебно-опытного лесхоза Воронежского лесотехнического института / М. Н. Грищенко // Научные записки Воронежского лесотехнического института. 1963. - Т. 29, вып. 2. - С. 3-13.

4. Казанская Н. С. Определение показателей рекреационной посещаемости и нагрузки / Н. С. Казанская, Н. Н. Марфенин, И. А. Воробьев // Теоретические и прикладные исследования природных комплексов. Москва : Географическое общество СССР, 1973. C. 25-27.

5. Казанская Н. С. Изменение экосистем под воздействием рекреации / Н. С. Казанская // Социальноэкономические и географические исследования территориальных рекреационных систем. - Москва : Б. и., 1980. - C. 94-105.

6. Мильков Ф. Н. Воронежская нагорная дубрава / Ф. Н. Мильков // По родным просторам. - Воронеж : Издательство Воронежского государственного университета, 1992. - С. 51-60.

7. Спесивый О. В. Структурно-функциональный анализ водосборных бассейнов Центрально-Черноземного региона для целей рационального природопользования / О. В. Спесивый // Современные проблемы науки и образования. - 2013. - № 6. - URL: www.scienceeducation.ru/113-11447.

8. Успенский К. В. Учебные экологические тропы в окрестностях Воронежа / К. В. Успенский. - Воронеж : Воронежский государственный педагогический университет, 2004. - 130 с.

9. Щербинина С. В. К опыту формирования и развития информационной компетенции через реализацию учебных практик по географическим дисциплинам в вузе / С. В. Щербинина // Территориальная организация общества и управление в регионах : материалы 12-й Всероссийской научно-практической конференции с международным участием. - Воронеж, 2018. C. $189-191$.

10. Лыжный спорт: новости лыжного спорта, биатлона, триатлона. - URL : https://www.skisport.ru/news/ rollerski/78367/

\section{REFERENCES}

1. Gosudarstvennyy prirodnyy zakaznik oblastnogo znacheniya «Voronezhskaya nagornaya dubrava» / Departament prirodnykh resursov i ekologii Voronezhskoy oblasti. - http//:www.dprvrn.ru/index.php/work/ osobo...prirodnye.../329-210613oopt

2. Grigor'yevskaya A. YA. Analiz flory goroda Voronezha / A. YA. Grigor'yevskaya, V. YA. KHripyakova, O. P. Bykovskaya // Geoekologicheskiye problemy ustoychivogo razvitiya gorodskoy sredy. - Voronezh, 1996. S. 236-238.

3. Grishchenko M. N. Geologicheskoye stroyeniye territorii uchebno-opytnogo leskhoza Voronezhskogo lesotekhnicheskogo instituta / M. N. Grishchenko // Nauchnyye zapiski Voronezhskogo lesotekhnicheskogo instituta. -1963. - T. 29, vyp. 2. - S. 3-13.

4. Kazanskaya N. S. Opredeleniye pokazateley rekreatsionnoy poseshchayemosti i nagruzki / N. S. Kazanskaya, N. N. Marfenin, I. A. Vorob'yev // Teoreticheskiye i prikladnyye issledovaniya prirodnykh kompleksov. - Moskva : Geograficheskoye obshchestvo SSSR, 1973. - S. 25-27.

5. Kazanskaya N. S. Izmeneniye ekosistem pod vozdeystviyem rekreatsii / N. S. Kazanskaya // Sotsial'no-ekonomicheskiye i geograficheskiye issledovaniya territorial'nykh rekreatsionnykh sistem. - Moskva : B. i., 1980. - S. 94-105.

6. Mil'kov F. N. Voronezhskaya nagornaya dubrava / F. N. Mil'kov // Po rodnym prostoram. - Voronezh : Izdatel'stvo Voronezhskogo gosudarstvennogo universiteta, 1992. - S. 51-60.

7. Spesivyy O. V. Strukturno-funktsional'nyy analiz vodosbornykh basseynov TSentral'no-CHernozemnogo regiona dlya tseley ratsional'nogo prirodopol'zovaniya / O. V. Spesivyy // Sovremennyye problemy nauki i obrazovaniya. - 2013. - № 6. - URL: www.science-education.ru/ 113-11447.

8. Uspenskiy K. V. Uchebnyye ekologicheskiye tropy v okrestnostyakh Voronezha / K. V. Uspenskiy. - Voronezh : Voronezhskiy gosudarstvennyy pedagogicheskiy universitet, 2004. - $130 \mathrm{~s}$. 
9. SHCHerbinina S. V. K opytu formirovaniya i razvitiya informatsionnoy kompetentsii cherez realizatsiyu uchebnykh praktik po geograficheskim distsiplinam v vuze / S. V. SHCHerbinina // Territorial'naya organizatsiya obshchestva i upravleniye v regionakh : materialy 12-y Vse-

\section{Спесивый Олег Викторович}

кандидат географических наук, доцент Военного учебно-научного центра ВВС «Военно-воздушная академия им. проф. Н. Е. Жуковского и Ю. А. Гагарина» (г. Воронеж), E-mail: vaiu@ mil.ru

\section{Щербинина Светлана Васильевна} кандидат географических наук, доцент кафедры природопользования факультета географии, геоэкологии и туризма Воронежского государственного университета, г. Воронеж, т. (473) 266-56-54, E-mail: svetas237@mail.ru

\section{Севрюков Сергей Тихонович}

старший преподаватель кафедры физического воспитания факультета физической культуры и безопасности жизнедеятельности Воронежского государственного педагогического университета, г. Воронеж, E-mail: sevryukovst@yandex.ru rossiyskoy nauchno-prakticheskoy konferentsii s mezhdunarodnym uchastiyem. - Voronezh, 2018. - S. 189-191.

10. Lyzhnyy sport: novosti lyzhnogo sporta, biatlona, triatlona. - URL : https://www.skisport.ru/news/rollerski/ $78367 /$

Spesivy Oleg Victorovitch

Candidate of Geographical Sciences, Associate Professor of the Military Educational and Scientific Centre of the Air Force, «Air Force Academy named after professor N.E. Zhukovsky and Yu. A. Gagarin», Voronezh, E-mail: vaiu@mil.ru

Shcherbinina Svetlana Vasil'yevna

Candidate of Geographical Sciences, Associate Professor of the Department of nature management of the Faculty of geography, geoecology and tourism, Voronezh State University, Voronezh, tel. 8(473) 266-56-54, E-mail: svetas237@mail.ru

Sevryukov Sergey Tichonovitch

Senior lecturer of the Department of physical education of the Faculty of physical culture and life safety, Voronezh State Pedagogical University, Voronezh, E-mail: sevryukovst@yandex.ru 